\title{
Poder e corrupção do Sacerdócio do Segundo Templo
}

\author{
Poder y corrupción del Sacerdocio del Segundo Templo
}

Power and corruption of the Second Temple Priesthood

\begin{abstract}
Resumo: No período do Segundo Templo, os reinos ptolomeus e selêucidas, envolveram o templo num sistema de triburos que gerou a distorção da função do sumo-sacerdócio. Facilitou a corrupção da função, a busca de riquezas e poder abusivo sobre a população que foi despojada de seus bens e desencorajada em sua fé. Este artigo tenta narrar sinteticamente tais eventos com base em 1 e 2 Macabeus e Flávio Josefo. A esta narração se soma uma breve análise do 4QMMT, um documento apresentando a interpelação de um grupo de sacerdotes, aqueles que estão ministrando de forma corrupta no templo.
\end{abstract}

Palavras-chave: Templo, sacerdote, corrupção, poder, crise.

Resumen: En el período del Segundo Templo los reinos ptolomeos y seléucidas involucraron al templo en el sistema de tributos que generó la distorsión de la labor del sumo sacerdocio. Facilitó la corrupción de la labor por la búsqueda de riquezas y poder abusivo sobre la población que fue despojada de sus bienes y desalentada en su fe. El presente artículo intenta narrar sintéticamente dichos acontecimientos basándose en 1 y 2 de Macabeos, y Flavio Josefo. A esta narración se suma un breve análisis de $4 \mathrm{QMMT}$, un documento que presenta la interpelación de un grupo de sacerdotes a aquellos que están ministrando de forma corrupta en el templo.

Palabras-Clave: Templo, Sumo Sacerdote, corrupción, poder, crisis.

Abstract: In the period of the Second Temple the Ptolemaic and Seleucid kingdoms involved the temple in the system of tributes that generated the distortion of the ministry of the High Priesthood. Facilitated the corruption of the Priesthood by the search of wealth and abusive power over the population that was stripped of its property and discouraged in its faith. The present article attempts to narrate these events synthetically based on 1 and 2 Maccabees, and Flavius Josephus. To this narration is added a brief analysis of 4 QMMT, a document that presents the interpellation of a group of priests to those who are ministering in a corrupted way in the temple.

Keywords: Temple, High Priest, Corruption, Power, Crisis. 


\section{Conquista griega y el sumo sacerdocio}

Cuando Alejandro murió en el 323 a.C., sus generales se dividieron el imperio griego. Inicialmente Israel quedó bajo el dominio del rey Ptolomeo. Bajo los nuevos gobernantes la autonomía política y religiosa de la comunidad judía fue mayor que con los persas, pero ya tenían la pesada carga del pago de tributos. En Israel, categorizada por los persas como un Estado-Templo, el Sumo Sacerdote quedó en la práctica como el representante político del pueblo, claro está, bajo la supervisión de un gobernador persa (SCHWARTZ, 1994, p. 160). Los persas se encargaron del establecimiento de ciertas familias sacerdotales que se ocuparían de la administración del Templo, y fueron los mismos persas quienes consolidaron la construcción del templo como política imperial para ganarse la buena voluntad de los retornados y de la población que habitaba Israel (HORSLEY, 2007, pp. 16-22).

El mismo Sumo Sacerdote fue el encargado del pago de los tributos a los persas. La forma y la fuente de donde conseguiría el dinero quedaron también bajo su responsabilidad (REICKE, 1965, pp. 34-36; SCHAPER, 1995, pp. 528-539). En el proceso de recaudación de impuestos las élites sociales estuvieron involucradas, por lo que debían de haber participado también de ciertas ganancias (ROSTOVTZEFF, 1967, pp. 346-349). En tiempos de los ptolomeos, y más en los de los seléucidas, el cargo de Sumo Sacerdote -a pesar de ser hereditariofue cambiando de mano en mano, de acuerdo a las urgencias de bienes de los reyes griegos. Ante esta situación, algunas familias de las élites sacerdotales vieron la obtención del cargo como una oportunidad de enriquecimiento bajo la autoridad.

En este período de la historia, Israel fue grandemente influenciada por el helenismo, como bien lo señala 2Macabeos (Cf. PASTOR, 2000, pp. 366s). Este fenómeno se dio en todas las áreas de la vida social, y aconteció especialmente entre las élites sociales y sacerdotales, dueñas de los medios de producción económica y grandes influyentes en las creencias y perspectivas del pueblo en torno al templo. Las necesidades de la vida cotidiana, por otro lado, hicieron indispensable que muchos en la población aprendieran elementalmente el idioma griego. La construcción de nuevas ciudades al estilo griego, con colonos militares, no sólo sirvió para la defensa del imperio, sino que fueron básicamente un centro de influencia de la cultura griega sobre las otras ciudades. 


\section{El reinado de Antíoco IV, el sumo sacerdocio y el Templo}

\subsection{Onías III y Jasón}

Antíoco IV, hijo de Antíoco III, el Grande, ascendió al trono seléucida en el año 175 a.C. El reinado de Antíoco IV estuvo lleno de contrariedades por los avances del imperio romano al cual le debía grandes sumas de dinero. Una de las medidas que tomó el rey para pagar sus deudas fue el incremento de los tributos a sus súbditos. En su insaciable necesidad de riquezas tomó las riquezas de los templos que estaban dentro de su dominio, incluyendo el pequeño templo de Jerusalén. Con relación a este hecho, Antíoco IV depuso del cargo al entonces Sumo Sacerdote Onías III (Josefo, Antigüedades, XX 10,3), y en su lugar puso a su hermano, que se hizo llamar "Jasón", versión helenizada del nombre hebreo Jesús o Josué. Jasón, un pro seléucida confeso, compró el cargo por una elevada suma de riqueza y prometió aumentar el canon anual que los judíos entregaban al tesoro de Siria (2Mac 3:1ss; 4:1-8; Cf. Josefo, Antigüedades, XII 160ss). La deposición y suplantación de Onías III fue de gran impacto en quienes veían en la institución del sacerdocio y del templo una instancia a través de la cual lograban el favor divino. En diferentes fuentes puede percibirse el aprecio hacia este Sumo Sacerdote, tanto por sus cualidades personales, pero más aún por su derecho truncado a través de la traición de su propio hermano. 2Mac 4:2 describe a Onías III como "defensor celoso de sus compatriotas y observante celoso de la Ley" (Cf. Dn 9:25, "el líder ungido"; y 11:22, "líder de la Alianza").

No debe olvidarse que la ideología detrás de la recaudación de tributos fue que el rey gobernante era el dueño absoluto de todas las tierras conquistadas, y esto, con el aval de sus dioses. Este parece haber sido el argumento que los reyes ptolomeos y seléucidas adoptaron, siguiendo las creencias de los pueblos de Oriente (HENGEL, 1974, pp. 18-32). Viéndolo de esta manera, este pago fue visto como un "tributo", un acto de veneración y de respeto al rey protector y dueño de la tierra. Que se involucrara a los Sumos Sacerdotes en esta actividad tenía claras intenciones políticas para hacer mella en la fe y la moral de la población que vería a sus líderes religioso-sociales involucrados sumisa, y/o de forma deshonesta, en las acciones del imperio conquistador y sus dioses. Este tributo negaba, de alguna manera, la soberanía del Dios de Israel sobre esta tierra, así como también la adjudicación de la misma a su pueblo. 
Si los Sumos Sacerdotes anteriores pudieron explicar su proceder hacia la obtención de los bienes del pueblo, con la excusa de la imposición de los reyes invasores, Jasón dejó en claro que su motivación fue acceder al poder, que lo hizo de forma corrupta, y que dicho poder le significaría, entre otras cosas, la obtención de grandes riquezas para él y sus allegados. Si el pueblo en general estaba o no al tanto de esto no se puede saber con seguridad, aunque es probable que los seguidores del depuesto Onías III hicieran correr su versión de la situación. El cargo se había convertido en una oportunidad de enriquecerse y lograr el poder político con el apoyo de los invasores. La adaptación al sistema imperial ya no era una mera imposición, sino una opción de crear una vida "cómoda" para algunos sectores privilegiados de la población, en detrimento de las grandes mayorías. Por lo que expresa 2 Mac 4:8, Jasón propuso pagar un tributo anual de 360 talentos, más un adicional de 150 talentos para tener el permiso de establecer un "gimnasio" en Jerusalén. Con este Sumo Sacerdote, la imagen de tal oficio sagrado cayó de su estima, y aún pudo haber quienes rechazaron el sumo sacerdocio y el servicio en el templo del todo. Las "aguas se dividieron" entre quienes re-elaboraron sus creencias bajo la influencia de la cultura helénica y quienes se resistieron, o bien salieron del sistema creando comunidades que les permitieran ser leales a Dios de acuerdo a su comprensión de la Ley (por ejemplo, comunidades esenias y, particularmente, la comunidad de Qumrán).

El uso de tal posición de poder le brindó a Jasón la oportunidad de imponer sus perspectivas haciendo de Jerusalén una ciudad cada vez más helénica. Por 2Mac 4:9 se sabe que un grupo de pobladores de las élites sociales de Jerusalén lograron ser ciudadanos de Antioquía, es decir gozar de muchos de los derechos y privilegios de los ciudadanos griegos libres del imperio seléucida (Cf. MORKHOLM, 1989, pp. 279s). Con la construcción del gimnasio se alistaron muchos jóvenes judíos que absorbieron la cultura helénica (1Mac 1:14-15). Detrás de esta medida también hay razones económicas: quieren convertir a Jerusalén en una ruta comercial en el imperio (GALLAZZI y RUBEAUX, 2015, p. 15). En su deseo de asemejarse a los griegos, estos jóvenes disimularon su circuncisión, haciendo a un lado el signo patriarcal de la alianza. Esta atracción hacia el gimnasio la tuvieron también algunos de los sacerdotes del templo, quienes se apuraban en su servicio -cuando no lo abandonaban- para apreciar los deportes (2Mac 4:14s). Hay que recordar que el gimnasio era un centro de deportes, de formación militar, 
de educación griega, así como también un medio social y sede de las cofradías religiosas. Estos centros permanecían cerrados a quienes no eran griegos o helenizados; de allí que los jóvenes y sacerdotes mencionados debieron ser abiertos seguidores de la cultura griega. Cabe mencionarse, con todo, que esta información y sus énfasis respondan al carácter anti-helénico que refleja 2 Macabeos. Si bien es cierto que algunos sacerdotes del templo participaban en las actividades helénicas, no significa que éstos quisieran abandonar su fe israelita. Más que una deserción, se trataba de una tendencia sincretista que algunos miembros del grupo sacerdotal fueron asumiendo (Cf. BICKERMAN, 1971, pp. 24-31).

Según las perspectivas de 2Macabeos, fueron los judíos helenistas quienes buscaron la helenización de Jerusalén, accediendo entusiastamente a las imposiciones culturales que el reino seléucida venía proponiendo (Cf. BRINGMANN, 1983, pp. 66-74). Es importante no caer en generalizaciones que distorsionen la noción de la realidad. Si bien es cierto, las fuentes con las que se cuentan no son muchas, cabe observar que los sectores más involucrados, aunque no exclusivamente, con el helenismo fueron las élites sociales que se vieron beneficiados con tal acercamiento (obsérvese el viejo estudio de TCHERIKOVER, 1959, pp. 186-203; Cf. HORSLEY, 1999, pp. 10-13). La mayoría de la población, el campesinado y los pequeños artesanos, debieron experimentar su vinculación con los conquistadores griegos desde la expropiación de sus bienes, en el pago de tributos, la captación de mano de obra barata, la expropiación de sus tierras por las deudas, entre otros. Estas nuevas condiciones de vida debieron construir su imaginario sobre el helenismo, además, claro está, de los hechos suscitados por el sacerdocio y otras organizaciones de liderazgo de la nación.

\subsection{Menelao}

Tres años después de la toma del cargo de Sumo Sacerdote 172 a.C.), Jasón fue depuesto para ser reemplazado por Menelao, quién ofreció una suma mayor para ocupar el cargo (2Mac 4:23ss). El monto que diera hacía cuatro años atrás se había duplicado con la nueva propuesta. Definitivamente, el sumo sacerdocio había perdido su santidad y estaba siendo usado para ostentar el poder y alcanzar los privilegios que con éste venían. Se puede pensar que para gran parte de la población, al tanto de estas situaciones, el sumo sacerdocio y la administración del templo se convirtieron en un centro de corrupción, 
un ejercicio sacrílego desde el cual se realizaban las mayores injusticias, la profanación de las fiestas religiosas y el despojo de los bienes y de las libertades de la población.

Si la destitución de Onías III había sido irregular, la instauración de Menelao rompió todos los cánones, puesto que no pertenecía a una familia sadoquita; y quizá ni siquiera fuese de alguna familia sacerdotal. Es posible que, ante esta nueva situación, ciertos sectores religiosos eligieran ponerse a lado de Jasón quien, al menos, pertenecía a una familia sadoquita (MORKHOLM, 1989, pp. 280s).

\subsection{Intervención directa de la administración de Antíoco IV}

En el año 169 a.C., en vista a sus grandes apremios económicos, Antíoco IV saqueó el Templo de Jerusalén con la ayuda de Menelao (2Mac 5:15-18). El rey seléucida retornó a Antioquía con 1800 talentos, un poco menos que el equivalente a tres años de tributos, de acuerdo a lo estipulado con el nuevo Sumo Sacerdote. En una segunda campaña de Antíoco IV en Egipto (168 a.C.), Jasón se levantó contra algunas disposiciones y funcionarios del rey seléucida. Éste volvió y arrasó con Jerusalén, que sufrió la muerte de mucha gente y el saqueo (2Mac 5:11-14). Tras estos sucesos, Antíoco decidió poner fin a todos los inconvenientes con el puesto de Menelao y envió a un delegado con medidas administrativas que afectaron el estatus del Templo. Parte de la población huyó al desierto donde no pudo ser alcanzada por las medidas seléucidas (HENGEL, 1974, p. 281; Cf. HORSLEY, 1999, pp. 15s). Que Jerusalén fuese considerada una ciudad griega tuvo una fuerte repercusión en la población. Significó que la vida no se legislaría principalmente por la Ley judía, que tenía aún gran influencia en la vida "civil". Esto también implicó que los judíos fueran desposeídos de su centro espiritual. Algunos investigadores ven la posibilidad de que en este tiempo se haya cambiado el antiguo calendario cultual de 364 días, adoptando el helenístico común (VANDERKAM, 1981, pp. 1-23; DAVIES, 1983, pp. 80-89).

Una segunda medida fue la imposición de un nuevo método de tasación de tributos. El tributo anual, que consistía en un monto determinado, sin mayores especificaciones en la forma de obtenerse, fue reemplazado por un impuesto proporcional a la tierra, recaudado directamente de la producción agrícola por agentes reales. Mientras que las élites sociales perdían sus privilegios y eran despojados de buena parte de sus riquezas, fue el pequeño campesinado quien sufrió aún más 
duramente las consecuencias de estas nuevas medidas. Es indudable que estos impuestos directos fueron más opresivos que los anteriores. Al parecer, llegaron a significar el treinta por ciento de la producción de grano (MORKHOLM, 1989, p. 285). Esta medida respondía en buena parte al fracaso de Menelao de juntar el monto que había prometido a los seléucidas. La corrupción de las autoridades del pueblo tenía, cada vez más, peores repercusiones en la población.

Poco tiempo después, otro golpe fue dado a los judíos piadosos. Un ateniense, Gerontas, llegó a Jerusalén enviado por Antíoco con un decreto real que tenía medidas muy duras para la vida religiosa y social de los habitantes de Judea (1Mac 1:41-53; 2Mac 6:1). Dichas regulaciones buscaban que todos formaran un único pueblo y abandonaran sus peculiares costumbres. Se suprimieron en el santuario holocaustos, sacrificios y libaciones; se prohibieron la circuncisión de los niños, la observación del sábado y de las fiestas; se confiscaron los rollos de la Ley, para luego ser quemados; se mancilló el santuario, ofreciéndose animales impuros; se obligó también a ofrecerse la celebración mensual del nacimiento del rey con un banquete sacrificial. Posteriormente se erigió un nuevo altar sobre el altar de los holocaustos y en el mismo se ofreció en sacrificio una cerda. Esta es la "abominación de la desolación" de la que habla el libro de Daniel. El cumplimiento de estas ordenanzas las ejecutaría una autoridad designada por Antíoco con el apoyo del Sumo Sacerdote Menelao.

Mientras que unos se sometieron a las imposiciones seléucidas, otros muchos judíos piadosos se fueron a regiones apartadas de las montañas o al desierto de Judea, prefiriendo dejar sus hogares que caer en la obediencia al decreto real (1Mac 2:29). Miles huyeron a los países limítrofes, estableciéndose en ellos y fundando comunidades para asegurar la relación social entre los emigrantes y hacer posible en aquellas regiones paganas una conducta piadosa, conforme a la Ley. Este acto seguramente fue visto por las autoridades como una especie de rebelión, puesto que la huida de los campesinos significaba sencillamente que la tierra era dejada sin dueño y sin mano de obra y, por lo tanto, resultaba en una disminución de los ingresos reales por los tributos.

Los pequeños propietarios campesinos tuvieron que vender sus propiedades en vista de no poder cumplir con los impuestos. Los colonizadores griegos, inmediatamente después de adquirir sus haciendas, compraron esclavos y/o contrataron jornaleros para que las trabajasen, gran parte de éstos fueron judíos (Cf. 2Mac 8:11; 3:41). Lo mismo de- 
bió suceder entre los propietarios judíos, puesto que esta práctica era atractiva por los grandes dividendos que traía. Esta realidad hizo que la gran masa de la población comenzara a tomar acciones y posturas, algunos poniendo una resistencia pacífica, no por ello menos efectiva (1Mac 1:62-63; 2 Mac 6:18-7:42), y otros en lo que sería más tarde la rebelión macabea, apoyada en buena manera por campesinos y aquellos jasidim que no siguieron más con su actitud pasiva inicial (Cf. GALLAZI, 1991, pp. 55-66; HORSLEY, 1999, p. 20).

\section{Insurrección macabea}

\subsection{Matatías}

Todo comenzó en el pueblo de Modín, al noroeste de Jerusalén, donde un anciano sacerdote de la orden de Joarib, llamado Matatías, vivía con sus cinco hijos (1Mac 2:1ss). Cuando un oficial del rey fue a ese pueblo a obligarle a ofrecer sacrificios, Matatías no sólo se rehusó a hacerlo, sino que también indignado mató a un judío que obedeció a la autoridad real, huyendo posteriormente con sus hijos y todos aquellos que bajo su convocatoria querían permanecer en la observancia de la Ley del Dios de Israel (1Mac 2:15-28; Josefo, Antigüedades, XII 265; 268-271). Muy pronto se unieron a sus filas los denominados jasidim (1Mac 2:42). Mientras que 2Mac 14:6 sostiene que éstos se unieron a los macabeos desde el principio, lo más probable es que haya sucedido como lo describe 1Mac 2:42. Éstos se consideraron "leales" a la alianza del Señor. Fue un movimiento que pregonó la conversión y obediencia radical a la Ley. Procedían principalmente de los sectores más pobres y de distintos lugares del país, pero en sus filas se contaba con algunas personas de familias prominentes.

El apoyo posterior de parte de los jasidim expresa de alguna forma las tensiones que sufrían los diferentes grupos del pueblo judío. Para los que optaron por la resistencia pacífica, el levantamiento de Matatías quizás fue considerado un acto en contra de la soberanía de Dios (VAN DER LINGEN, 1990, p. 183). Sin embargo, no ha de perderse de vista que la insurrección surgía en medio de tensiones entre dos bandos de la élite judía que, a final de cuentas, parecían mostrar poco interés en el pueblo y sí en mantener fuertes vínculos con los griegos y sus métodos. Por otro lado, Matatías no era sacerdote sadoquita y no había pasado suficiente tiempo para conocer sus intenciones con la insurrección. 


\subsection{Judas}

En el año 166/165 a.C., un tiempo después de su levantamiento, Matatías murió, convirtiéndose en un héroe nacional. Lo sucedió su hijo Judas, apodado "macabeo", como comandante del ejército, y su otro hijo, Simón, como asesor (1Mac 2:49-70; Josefo, Antigüedades, XII 279286). En el año 164 a.C., tres años después de las medidas tomadas por Antíoco, Judas consiguió tomar Jerusalén, y el templo fue purificado y dedicado nuevamente bajo el liderazgo de Judas (1Mac 4:36 y ss.; 2 Mac 10:1-7; Josefo, Antigüedades, XII 316-326). En ese mismo año (164 a.C.) murió también Antíoco IV, mientras realizaba una campaña en Persia (1Mac 6:1-13). Lisias se autoproclamó protector del heredero Antíoco

$\mathrm{V}$ quedando él, en la práctica, como soberano del reino seléucida (1Mac 6:14-17; Josefo, Antigüedades, XII 360-361).

Tras un petitorio de los judíos helenistas que se quejaban de los abusos de Judas, Lisias organizó un poderoso ejército para enfrentarlo (1Mac 6:18-30; Josefo, Antigüedades, XII 364-366); después de una serie de enfrentamientos, en el año 162 a.C. Judas fue derrotado y su hermano Eleazar asesinado. El avance de Lisias fue hasta las mismas murallas de Jerusalén (1Mac 6:28-48; 2 Mac 13:15-17; Josefo, Antigüedades, XII 369-375; Guerra, I 41-46). Cuando parecía que todo estaba perdido, un enfrentamiento interno obligó a Lisias a retirarse de Jerusalén y hacer las paces con Judas. En esta ocasión le concedió los derechos que los judíos ejercieran libremente su religión (1Mac 6:55-62; 2 Mac 13:23-26; Josefo, Antigüedades, XII 379-383). Esta concesión nunca fue revocada por los reyes griegos que tuvieron dominio sobre Israel. En este acontecimiento muchos vieron colmados los objetivos primeros de la insurrección macabea. A consecuencia de estos sucesos, los helenizantes de Judea perdieron la dirección de los asuntos públicos. Sin embargo, los conflictos que siguieron respondieron a la búsqueda del control del pueblo judío entre las facciones más tradicionalistas y las pro-griegas.

\subsection{Jonatán}

Una serie de acontecimientos marcó la época y el liderazgo de la familia macabea. Nuevamente un rey seléucida nombró a un Sumo Sacerdote que respondiera a sus intereses, llamado Alcimo (1Mac 7:5-9; 2 Mac 14:3-10; Josefo, Antigüedades, XII 391-393). Hubo algunos que vieron en este nombramiento una vuelta a la "normalidad", puesto que Alcimo procedía de la familia sadoquita, aunque no de la familia 
oníadas. Tras la muerte de Judas, lo sucedió su hermano Jonatán (1Mac 9:28-31; Josefo, Antigüedades, XIII 5-6). Este nuevo líder estableció un gobierno paralelo al del Sanedrín oficial de Jerusalén. Esta organización se convirtió, de forma paulatina, en la fuerza principal del país con la consecuente persecución de los sectores helenistas (1Mac 9:73).

Con el apoyo del pretendiente al trono seléucida Alejandro Balas, Jonatán asumió el cargo de Sumo Sacerdote el año 153 a.C. (1Mac 10:15-21; Josefo, Antigüedades, XIII 43-46). El libro de 1Macabeos no hace ninguna crítica ante tal irregularidad mostrando su simpatía por esta familia. No se conoce bien cuál fue la reacción inicial de la población. Lo cierto es que las familias más tradicionales y vinculadas a sacerdocio sadoquita debieron estar disconformes con esta elección. Con todo, y una vez más, el sumo sacerdocio estaba vinculado a una decisión seléucida. Mientras que por decenios las familias sadoquitas habían monopolizado ese cargo tan influyente (Cf. LE MOYNE, 1972, pp. 63-93), ahora este grupo quedaba excluido de sus privilegios y del centro físico de influencia sobre el pueblo, que les confería grandes privilegios con los reyes extranjeros de turno. Por otro lado, el cargo de Sumo Sacerdote concedido a Jonatán consolidó, al menos por un tiempo, la causa macabea en el poder. Al obtener el cargo político-religioso, el líder macabeo institucionalizó su influencia sobre el pueblo y sobre sus enemigos internos, fortaleciendo sus vínculos con las naciones extranjeras.

\subsection{Simón}

En el año 143 a.C., Jonatán fue tomado prisionero, por una traición de Trifón general del rey Antíoco VI, y ejecutado en Bascama (1 Mac 12,39-53; Josefo, Antigüedades, VI 203-212). Este líder judío había logrado consolidar de gran manera la causa macabea, y el territorio judío alcanzó una gran extensión. Simón, que era el único superviviente de los cinco hermanos macabeos, se hizo cargo de la jefatura. Por una serie de eventos ajenos, en el año 142 a.C., Simón logró cierta autonomía política. En consecuencia, a partir de ese mismo año los judíos comenzaron a usar su propia cronología (1Mac 13,33-42; Cf. 14,27 y Josefo, Antigüedades, XIII 43-46). Finalmente, también fue tomada la ciudadela de Jerusalén, transformándola en un palacio (1Mac 13,51). Se trataba de un acto muy significativo, que marcaba la total independencia del poder seléucida en la capital de los judíos. 


\section{Los reyes asmoneos}

Debido a la extensión de este artículo, no nos podemos alargar demasiado en este período. Vale decir que con la independencia política de Israel comenzó la llamada era "asmonea". El 140 a.C., en una reunión de la asamblea popular de los judíos, se decretó en consideración a las hazañas patrióticas de Simón y sus hermanos, que éste fuese oficialmente nombrado comandante en jefe del ejército, etnarca o gobernador de la nación y sumo sacerdote. Simón había tomado de Jonatán, juntamente con la jefatura de las funciones civiles y militares, el sumo sacerdocio que Alejandro Balas le había conferido a su hermano. Pero no era aceptable que el Sumo Sacerdote de una nación libre mantuviera la sagrada dignidad conferida por un monarca extranjero, y además dicho cargo había sido tomado en una situación coyuntural de gran adversidad y en la que se precisaba de un líder religioso y militar. 1 Mac 14,25-49 expresa su gran admiración por este líder y cuenta de una votación popular en la que Simón fue ratificado en sus cargos, entre ellos el de Sumo Sacerdote. Estos cargos serían "para siempre", es decir hereditarios. Sin embargo, a pesar del gran consenso del pueblo, es más que seguro que hubo sectores que rechazaron tales designaciones, en particular la del sumo sacerdocio. Sobre todo, las familias sacerdotales o grupos religiosos (jasidim, fariseos, sadoquitas y la comunidad de Qumrán) que querían conservar las tradiciones veterotestamentarias que legitimaban a las familias sadoquitas, como aquellas que habían sido designadas para tal función (Cf. 1Mac 14,27-49). Los acontecimientos que siguieron estuvieron marcados por idas y vueltas en torno al liderazgo en el templo, expresiones de exceso o mal uso del poder que distorsionó, al menos ante los ojos de algunos sectores de la población, lo que los macabeos habían iniciado. Todo había sido muy rápido, y tras el historial de pugnas por el poder, de hechos corruptos para obtener el sumo sacerdocio y aun en la obtención de los tributos, la asunción de Simón y sus sucesores al liderazgo, más tarde reinado, y al sumo sacerdocio devino en nuevos actos de corrupción, en la postergación de los intereses de las mayorías, y en la toma de privilegios para una familia que ostentaría por varias décadas el poder.

\section{4QMMT ("algunos de los preceptos de la Torá")}

Este documento nos ilustra las luchas de poder y casos de corrupción entre facciones sacerdotales relacionadas al Templo de Jerusalén. Esto a manera de ilustración de una de los muchos enfrentamientos y 
razones para ellos que debieron darse en este período. Llamada también "Carta Halákica", se trata de un documento enviado inicialmente al Sumo Sacerdote (Cf. "para ti y para tu pueblo..." 4QMMT 113. Cf. QIMRON y STRUGNELL, 1994, pp. 117-118 y 121) ${ }^{1}$ y/o a un grupo de sacerdotes (SCHIFFMAN, 2000, p. 558) que siguieron ministrando en el templo mientras que los autores aparentemente decidieron salir de dichas funciones en vista de las impurezas que se estaban cometiendo. En términos generales se trata de un escrito que contiene en su cuerpo central disposiciones respecto a las ofrendas, la pureza y temas afines, que son presentados en términos de discrepancia con las prácticas actuales que eran consideradas impuras. En el epílogo del documento está el llamado a un líder a enmendarse, mientras le sea posible, en base al juicio de Dios que llegará de forma inminente.

Las posibles identificaciones de los autores son diversas. En parte la complejidad se debe a que el documento actual, en sus cinco copias, refleja un largo proceso de composición. Así, hay secciones donde el autor habla en primera persona en singular (yo), y otras en la que lo hace en plural (nosotros). También respecto a los destinatarios, hay partes en la que se dirige a una persona en singular (tu) y otras en plural (ustedes). La identificación de estos sujetos es motivo de discusión. Los documentos en su estado actual reflejan trabajos de edición que comprenden un período de cerca de 100 años, es decir entre los años 150 y 50 a.C. (WEISSENBERG, 2006, pp. 16-25). Para el tema que se está tratando aquí nos interesa que se hable claramente de dos grupos de sacerdotes que están enfrentados en sus perspectivas respecto a la pureza y la correcta ministración de los rituales en el templo. Este sencillo análisis nos servirá de ilustración de un caso, de los muchos que debieron darse, de disputas teológicas, prácticas adaptadas a las ideologías de los nuevos poderes extranjeros y autóctonos, así como también a la forma como se concibió la lealtad a Dios en esas circunstancias.

En 4QMMT 92 se dice explícitamente: "Y ustedes saben que nos hemos separado de la mayoría del pueblo... de mezclarnos en estos asuntos". Esto es dicho en el contexto en el que se están señalando los errores en los que caen los sacerdotes del templo. No se describe en

Seguimos la reconstrucción del texto y la traducción de F. García Martínes, Textos de Qumrán, Madrid: Trotta, 1992, pp. 127-130, y el texto hebreo de F. García Martínez y Eibert J. C. Tigchelaar, The Dead Sea Scrolls. Study Edition, Leiden: Brill, 1997, pp. 790-804, salvo se señale alguna modificación. 
este texto que la salida de los autores haya sido violenta, pero por la tensión reflejada en el texto, la separación no fue voluntaria. Lo que sí está claro es que estos sacerdotes se han separado de sus labores del templo, mientras que dirigen sus observaciones a quienes permanecieron o bien los han sustituido (4QMMT 82b-85).

1. El primer tema que se menciona como discordante y motivo de la separación de los autores del escrito es "el calendario". Quienes suscriben este documento observan un calendario solar correspondiente a 364 días, un calendario basado en el sábado (Cf. GARCIA MARTINEZ, 2004, pp. 157-175; VANDERKAM, 1991, pp. 52-74). Como se puede apreciar en $2 \mathrm{Mac} 6$, el calendario tradicional judío había sido modificado de tal manera que se priorizaron las celebraciones de los reyes y dioses griegos. No se sabe bien cuáles fueron, con precisión, tales modificaciones, pero debieron afectar la cronología que hacía que ciertas festividades no se superpusieran al sábado, que los ciclos de servicio sacerdotal en el templo tuvieran una armonía en la secuencia de los turnos, así como también que el inicio de la temporada climatológica coincidiera con el tiempo de la siembra y la cosecha. El cambio del calendario no fue un hecho menor. La noción del Dios de Israel como quien ha creado el universo y ha organizado todo armoniosamente es una creencia muy importante en el período del Segundo Templo (GARCIA MARTINEZ, 2004b, pp. 157-175). Especialmente en tiempos de tanto "caos", de cambios rotundos de dirección de la vida, la fidelidad al calendario litúrgico sirvió de apoyo para el encuentro con un Dios que tenía control de su creación, más allá de las acciones humanas. Las discrepancias en torno al calendario posiblemente se dieron por la adaptación de las fiestas sagradas y en los rituales según las disposiciones seléucidas que pretendieron instalar su lógica de la vida y del mundo, basados en las creencias en sus dioses (ver arriba).

2. Otro tema llamativo es presentado en 4QMMT 6-16a. En el texto se pueden observar varios actores diferentes: "tú" (tácito), "nosotros", "los gentiles", "ellos", “sacerdotes” e "hijos de Aarón”. En la línea 6-7 (Cf. líneas 9, 11, 13) se habla de "ellos". En algunos casos es más claro que se refiere a los gentiles, pero en otros parece referirse tanto a los gentiles como a los sacerdotes que ofician para ellos. Siendo que se trata del sacrificio, podría pensarse que se trata de los sacerdotes, sin embargo, a ellos se les identifica como tales "sacerdotes" (Cf. línea 15) 
y, por otro lado, la referencia alude al acto de impureza que trae consigo el aceptar el cereal de los gentiles dentro del Templo ("y lo tocas [...] y lo profa[nan]: no lo comeréis"). En el mismo hilo de prácticas erradas está el permitir a los gentiles ofrecer sacrificios, es decir poner la mano sobre la cabeza del animal (Cf. Lev 1 y 4). La reconstrucción de Vermes (2004, pp. 224-225) incluye en una laguna "[nosotros decimos que ellos sacrifican] 12 [a los ídolos ...]". Esta última frase no aparece en la traducción y reconstrucción de García Martínez-Tigchelaar, pero nos señala que este investigador ve en el texto una alusión negativa al acceso de los gentiles al sacrificio.

Evidentemente, la práctica de gentiles entregando ofrendas y ofreciendo sacrificios ya sucede en el templo (2Mac 3:32-35; Cf. M. Sheqalim 1:5). Esta práctica no puede ser muy antigua, puesto que se presenta como motivo de separación. Las perspectivas etnocéntricas en la comunidad de Qumrán no son exclusivas de ella; en otros escritos intertestamentarios pueden percibirse, por ejemplo, en el libro de Jubileos, que tuvo un carácter normativo para varios grupos de la época. Vistas en el contexto, puede pensarse que el ingreso de ofrendas por parte de gentiles estaba ligada también a cambios realizados como expresión de apertura a los gentiles y si no a todos, a aquellos vinculados al poder.

3. En la misma dirección puede citarse 4QMMT 90b-92. El texto sigue a Deut 12,2; 7,26 y 12,31 (obsérvese el uso de terminología en común). El término "abominación" refiere precisamente al ingreso de ídolos en el templo (Cf. WEISSENBERG, 2009, pp. 191-201). La "violencia" y la "fornicación" mencionadas están relacionados, por otro lado, a la unión de los sacerdotes, "la simiente santa" (línea 82) con mujeres extranjeras. Este texto señala las prácticas actuales del sacerdocio del templo como "abominaciones" en vista a las faltas que se comenten, a la impureza de quienes realizan los rituales y posiblemente a una suerte de prácticas sincretistas que incluyen elementos ajenos a las viejas tradiciones y prescripciones referentes a la santidad del templo y de quienes oficiaban en él. Una vez más sucede que el sacerdocio vinculado al templo está corrompiendo viejas enseñanzas que les podría permitir convivir en armonía con los gentiles vinculados al poder de turno, pero que a los ojos de los autores del documento, los hace cometer abominaciones que contaminan el templo de Dios y del pueblo de Dios. 
4. Un último aspecto que se puede observar en este documento, con relación a la corrupción del templo, está en 4QMMT 103-112a. La alusión a las bendiciones y maldiciones ya se han mencionado arriba. Sin embargo, llama aquí la atención la mención a varios reyes del linaje davídico que cometieron errores y a que fueron castigados por ellos. La frase: “...para ti y para tu pueblo..." puede aludir a una figura de poder en Israel, quizás un rey asmoneo, o bien un Sumo Sacerdote. El texto señala la importancia que tiene las decisiones y la pureza que tenga ese líder, no solamente para el bien de su persona, sino y, sobre todo, para el pueblo. Ese mismo sentir se ha expresado respecto al actuar de los sacerdotes. Se dice que ellos en sus errores "inducen al pueblo en culpa" (línea 16a). Desde las perspectivas del autor/es del documento, la responsabilidad de reyes y sacerdotes del templo es grande, porque tuercen las enseñanzas recibidas, y por su influencia sobre la población entera los llevan hacia el pecado. Así, la corrupción y el mal manejo del poder es visto como un mal social al que ellos llaman a enmendarse. Su llamado incluye tanto el corregir sus prácticas erradas, como el hacer a un lado a quienes enseñan el error.

En 4QMMT 115-116 se dice: “...y aleje de ti la maquinación malvada y el consejo de Belial, de manera que puedas alegrarte al final del tiempo en el descubrimiento de que algunas de nuestras palabras son verdaderas". El dirigirse a un líder le concede libertades que personas en otras situaciones no pueden tener. Es importante advertir que la demanda a alejarse de la maldad es sugerida por un grupo de personas que ha corrido riesgos por hacerlo. La radicalidad de su llamado a la pureza, por lo que sabemos de la comunidad de Qumrán, está estrechamente vinculada a las opciones de vida radicales asumidas por los autores. Si bien es cierto estas acciones no fueron las únicas tomadas por quienes quisieron ser fieles a la Ley, y por ella al Dios de Israel, es de resaltar que su radicalidad consistió en la toma de conciencia de los perversos efectos de la corrupción del liderazgo del templo en la población, así como también tales reclamos surge de quienes han asumido los riesgos de no participar de dicha corrupción y de generar, como se puede saber por los textos de Qumrán, de un grupo de personas que buscó vivir voluntariamente fiel a los preceptos divinos en términos de santidad, justicia, pobreza, vida comunitaria, entre otros. 


\section{A manera de síntesis}

Algunos puntos que valen resaltarse a manera de repaso son:

1. El sistema de tributos ptomoleo y seléucida puso su base en la institución del templo de Jerusalén, bajo la responsabilidad del Sumo Sacerdote, tal cual lo hicieron antes los persas. Estratégicamente esto causó la vinculación del poder invasor con una organización religiosa de alta influencia en la población, llevó al desprestigio a esta última, y con ello generó un clima de gran ambigüedad, división y descontento en la población israelita. Es un error mirar la corrupción del sumo sacerdocio y el templo como un hecho "personal" e interno del pueblo israelita. No se puede explicar su existencia y alcance sin la intervención y apoyo de los conquistadores.

2. En la metodología inicial de recaudación de tributos estuvo darle "libertad" a los Sumo Sacerdotes y allegados sobre la metodología y criterios de recaudación. Esta arbitrariedad hizo que recaiga en éstos la responsabilidad de tales expropiaciones, lo cual llevó al desprestigio del sumo sacerdocio y del templo. La recaudación muy probablemente fue mayor a la exigida y sirvió a modo de enriquecimiento a estas castas sociales.

3. La corrupción del sumo sacerdocio y el templo fue creciendo en estrecho vínculo con los acontecimientos militares, políticos y culturales suscitados por los reinos invasores. Con el tiempo, de forma interna, las familias de las élites sociales y religiosas se pelearon, literalmente, por el puesto de Sumo Sacerdote y el apoyo del poder invasor. Llegaron a niveles de corrupción tales que aumentaron las ofertas de tributo, siendo que esto significaba mayor expropiación, injusticia y miseria para el pueblo.

4. Esta imagen tan negativa de los hechos en torno al templo de Jerusalén deben matizarse con las nuevas búsquedas de lealtad a Dios por parte de quienes decidieron separarse de esa institución antes que corromperse -ejemplo, el grupo detrás de 4QMMT- o bien rebelarse como lo hicieran los macabeos. Muchos grupos y movimientos religiosos surgieron en este período de invasión griega, algunos bastante distanciados del templo y del sumo sacerdocio, por ejemplo, el movimiento 
enóquico (1Enoc 89:72-90:17 y la crítica a los "pastores", refiriéndose a los sacerdotes del templo).

5. El levantamiento de los macabeos y el reinado de los asmoneos reorganizaron por un tiempo la vida del pueblo bajo los preceptos de la Ley que abogaba por el bienestar común. Sin embargo, especialmente en este segundo período, volvieron a corromperse los líderes del pueblo usando mecanismos similares a aquellos usados por los invasores. Todo parece indicar que los mecanismos donde había acumulación de poder en una persona o un pequeño grupo conllevaba la corrupción de las instituciones, tanto religiosas como políticas. Con todo, el surgimiento de movimientos que salieron del sistema corrupto, fue criticado y combatido, lo que señala el hecho que la "denuncia" no era suficiente si no se daba con la construcción de nuevas realidades.

\section{Bibliografía citada}

BICKERMAN, Elias (1979). The God of the Maccabees: Studies on the Meaning and Origin of the Maccabean Revolt. Leiden, Brill.

BRINGMANN, Klaus (1983). Hellenistische Reform und Religionsverfolgung in Judäa. Eine Untersuchung zur jüdisch-hellenistischen Geschichte (175-163 v. Chr.). Gotinga: Vandenhoeck \& Ruprecht.

DAVIES, Philip (1983). "Calendrical Change and Qumran Origins: An Assesment of VanderKam's Theory" Catholic Biblical Quartely 45, pp. 80-89.

GALLAZZI, Sandro (1991). "Es mejor morir en batalla que ver la desgracia de nuestro pueblo. El ejército popular en 1 Macabeos". Revista de Interpretación Bíblica Latinoamericana 8, pp. 55-66.

Y F. RUBEAUX (2013). Primeiro Livro dos Macabeus. Sao Paulo: Fonte Editorial.

GARCIA MARTINEZ, Francisco (Ed. y Trad). (1992). Textos de Qumrán, Trotta: Madrid.

y E. J. C. TIGCHELAAR (Eds. y Trads). (1997). The Dead Sea Scrolls. StudyEdition, 2 vols. Leiden: Brill.

(2004). “Literatura jurídico-religiosa de Qumrán”, en Paganos, judíos y cristianos en los textos de Qumrán. Edit. J. Trebolle Barrera. Madrid: Trotta, pp. 155-179.

(2004b). "Calendario de Qumrán", en Para comprender los manuscritos del Mar Muerto. Ed. J. Vázquez. Navarra: Verbo Divino, pp. 157-175. 
HENGEL, Martin (1974). Judaism and Hellenism. Studies in their Encounter in Palestine, Vol I. Londres: Fortress Press.

HORSLEY, Richard (1999). Bandits, Prophets and Messiahs. Popular Movements in the Time of Jesus. Pensilvania: Trinity Press International. (2007). Scribes, Visionaries and the Politics of Second Temple Judea. Louisville: Westminster John Knox Press.

LE MOYNE, Jean (1972). Les Sadducéens. París: Librairie Lecoffrea.

LINGEN, Anton van der (1990). Les Guerres de Yahvé. L'implication de YHWH dans les guerres d'Israël selon les livres historiques de l'Ancien Testament. París: Cerf.

MORKHOLM, Otto (1989). “Antiochus IV”, en The Cambridge History of Judaism, Vol. II, edits. D. Davies y L. Finkelstein. Cambrigde: University Press, pp. 278291.

PASTOR JULIAN, V. (2000). „Historia helenística: los Libros de los Macabeos“, en Introducción al Estudio de la Biblia 3b: Historia, narrativa, apocalíptica. Eds. A. González Lamadrid y otros. Navarra: Verbo Divino.

QIMRON, E. y STRUGNELL, J. (1994). Miqsat Ma'ase ha-Torah, Discoveries of the Judean Desert 10: Qumran Cave 4.V, Oxford: Clarendon Press.

REICKE, Bo (1965). Neutestamentliche Zeitgeschichte. Berlín: Alfred Töpelmann.

ROSTOVTZEFF, M. (1967). Historia social y económica del mundo helenístico, Vol. I. Madrid: Editorial Espasa - Calpe.

SCHAPER, J. (1995). "The Jerusalem Temple as an Instrument of the Achaemenid Fiscal Administration", Vetus Testamentum 45, pp. 528-539.

SCHIFFMAN, Lawrence (2000). “Miqtsat Ma'asei Ha-Torah”, en Encyclopedia of the Dead Sea Scrolls, vol 2. Edits. L. Schiffman y J. VanderKam. Oxford: University Press, pp. 558-560.

SCHWARTZ, Seth (1994), "On the Autonomy of Judaea in the Fourth and Third Centuries B.C.E, Journal of Jewish Studies 45, pp. 157-168.

VANDERKAM, James (1981). "2 Mace 6 7a and Calendrical Change in Jerusalem," Journal for the Study of the Judaism 12, pp. 1-23.

VERMES, Geza (2004). The Complete Dead Sea Scrolls in English, 4th ed. Londres: Penguin Books.

WEISSENBERG, Hanne von (2009). 4QMMT. Reevaluating the Text, the Function, and the Meaning of the Epilogue. Leiden: Brill. 